\title{
Adoptive cell therapy with autologous tumor infiltrating lymphocytes and low-dose Interleukin-2 in metastatic melanoma patients
}

Eva Ellebaek ${ }^{1,2}$, Trine Zeeberg Iversen ${ }^{1,2}$, Niels Junker ${ }^{1,2}$, Marco Donia ${ }^{1,3}$, Lotte Engell-Noerregaard ${ }^{1,2}$, Özcan Met ${ }^{1,2}$, Lisbet Rosenkrantz Hölmich", Rikke Sick Andersen', Sine Reker Hadrup ${ }^{1}$, Mads Hald Andersen ${ }^{1}$,

Per thor Straten ${ }^{1}$ and Inge Marie Svane $e^{1,2^{*}}$

\begin{abstract}
Background: Adoptive cell therapy may be based on isolation of tumor-specific T cells, e.g. autologous tumor infiltrating lymphocytes (TIL), in vitro activation and expansion and the reinfusion of these cells into patients upon chemotherapy induced lymphodepletion. Together with high-dose interleukin (IL)-2 this treatment has been given to patients with advanced malignant melanoma and impressive response rates but also significant IL-2 associated toxicity have been observed. Here we present data from a feasibility study at a Danish Translational Research Center using TIL adoptive transfer in combination with low-dose subcutaneous IL-2 injections.

Methods: This is a pilot trial (ClinicalTrials.gov identifier: NCT00937625) including patients with metastatic melanoma, PS $\leq 1$, age $<70$, measurable and progressive disease and no involvement of the central nervous system. Six patients were treated with lymphodepleting chemotherapy, TIL infusion, and 14 days of subcutaneous low-dose IL-2 injections, 2 MIU/day.

Results: Low-dose IL-2 considerably decreased the treatment related toxicity with no grade 3-4 IL-2 related adverse events. Objective clinical responses were seen in 2 of 6 treated patients with ongoing complete responses (30+ and 10+ months), 2 patients had stable disease (4 and 5 months) and 2 patients progressed shortly after treatment. Tumor-reactivity of the infused cells and peripheral lymphocytes before and after therapy were analyzed. Absolute number of tumor specific T cells in the infusion product tended to correlate with clinical response and also, an induction of peripheral tumor reactive T cells was observed for 1 patient in complete remission.
\end{abstract}

Conclusion: Complete and durable responses were induced after treatment with adoptive cell therapy in combination with low-dose IL-2 which significantly decreased toxicity of this therapy.

Keywords: Adoptive cell therapy, Tumor infiltrating lymphocytes, Malignant melanoma, Low-dose Interleukin-2

\section{Background}

The incidence of malignant melanoma is increasing and every year more than 68.000 Americans will be diagnosed with this disease [1]. Most patients are cured after resection of the primary tumor but for approximately $15 \%$ the disease will metastasize. Once disseminated, malignant melanoma has a very poor prognosis with a

\footnotetext{
* Correspondence: imsv@regionh.dk

${ }^{1} \mathrm{CCIT}$, Center for Cancer Immune Therapy, Department of Hematology, Copenhagen University Hospital, Herlev, Denmark

${ }^{2}$ Department of Oncology, Copenhagen University Hospital, Herlev, Denmark Full list of author information is available at the end of the article
}

5-year survival rate of less than 15\% [1]. Chemotherapy and radiotherapy have limited efficacy, and treatments with curable potential have been restricted to Interleukin(IL)-2 and Interferon(IFN)- $\alpha$ which has high toxicity, and low response rates. Recently, several new treatment modalities have been approved for the treatment of metastatic melanoma. This includes the anti-CTLA-4 antibody, Ipilimumab [2,3] and the B-RAF inhibitor, Vemurafenib [4], along with new drugs in the pipeline, e.g. PD-1 antibodies [5,6] and MEK-inhibitors [7]. Still, a large majority of the patients will eventually progress on 
these therapies leaving a need for additional treatment modalities with curable potential.

Adoptive cell therapy (ACT) with tumor infiltrating lymphocytes (TILs) was pioneered by Rosenberg and coworkers and has shown very promising results with high response rates and long-term survivors [8-10]. Despite this, the treatment has only been applied in a few centers around the world. The complicated procedure of establishing and expanding TIL cultures is one reason but also the toxicity of high-dose IL-2 limits the implementation of this therapy. IL-2 is administered to support further proliferation and persistency of the transferred $\mathrm{T}$ cells but whether high doses of IL-2 is required for induction of clinical response is not known. In a previous study [11], varying doses of IL-2 were administered together with antigen-specific $\mathrm{T}$ cells, but the optimal dose of IL-2 administered with TILs remains to be determined.

This pilot study was designed to investigate the feasibility of ACT using low-dose subcutaneous IL-2 injections instead of high dose intravenous IL-2. The objectives were to examine the toxicity profile, to evaluate the possibility of inducing complete and long-lasting clinical responses and to investigate potential immune parameters. Results from this trial, including safety data, clinical and immunological outcome are reported in the following.

\section{Materials and methods \\ Patients}

Patients between ages of 18-70 years with metastatic malignant melanoma were included. Further inclusion parameters were disease in progression (according to response evaluation criteria in solid tumors (RECIST)), measurable disease according to RECIST, at least one resectable metastasis at a minimum of $1 \mathrm{~cm}^{3}$, and performance status $(\mathrm{PS}) \leq 1$. Furthermore, patients had to be seropositive for EBV antigen and negative for hepatitis $\mathrm{B}$ and $\mathrm{C}$ infection and HIV. Exclusion criteria were significant heart or lung disease, autoimmune disease, other neoplastic tumors within the last 5 years, treatment with steroids, or involvement of the central nervous system.

All patients signed a written informed consent before entering the study.

\section{Treatment and trial design}

The trial was approved by the medical agencies, the ethical committees and the data agency, and was conducted in accordance with the Helsinki declaration and good clinical practice as described by Danish law (ClinicalTrials.gov ID: NCT00937625).

Patients were admitted to hospital at day -8 and a central venous catheter was applied. A lymphodepleting chemotherapy regimen consisting of Cyclophosphamide, $60 \mathrm{mg} / \mathrm{kg} / \mathrm{d}$ day -7 to -6 and fludarabine phosphate, $25 \mathrm{mg} / \mathrm{m} 2 / \mathrm{d}$ at day -5 to -1 administered as previously described [10]. Prophylactic antiemetics with palonosetron, aprepitant, and Domperidone were given together with pantoprazole. At day 0 autologous TILs were infused intravenously followed by 14 days of subcutaneous IL-2 injections, 2 MIU, starting the same evening.

Patients were treated prophylactically with trimethoprim, sulfamethoxazole, and acyclovir from the beginning of treatment and 6 months thereafter and with fluconazole during the leucopenic period.

Clinical response was monitored with a computed tomography (CT) or positron emission tomography (PET)/CT scan 8 weeks after T cell infusion and assessed according to RECIST 1.0. All scans were reviewed by an independent radiologist at the Hospital who was blinded to previous descriptions.

\section{TIL culturing and expansion}

Tumor material was obtained by excision of subcutaneous nodules (5 patients) or lymph nodes (6 patients). The tumor specimen was excised aseptically and transported in AIM-V (Invitrogen, Nærum, Denmark) media containing Fungizone. The TIL culturing method has been adapted from Dudley et al. [12] and has previously been described [13]. Briefly, the tumor sample were cut into 1-2 $\mathrm{mm}$ fragments and placed in 24 well-culture plates (Nunc, Roskilde, Denmark) together with $2 \mathrm{ml}$ of culture medium (90\% RPMI 1640 (Invitrogen), 10\% heat inactivated Human AB serum (Sigma-Albricht, St. Louis, MO, USA), IL-2 $6000 \mathrm{IU} / \mathrm{ml}$ (Aldesleukin, Novartis, Basel, Suisse), penicillin, streptomycin and fungi zone (Bristol-Myers Squibb, Lyngby, Denmark). Cells were split into 2-3 wells when cell concentration in 1 well exceeded $1.5 \times 10^{6}$ cells $/ \mathrm{ml}$. Each fragment and the following TIL cultures were kept separate during further expansion. Cell counting and viability testing were stained with tryphan blue and analyzed by microscopy.

TIL cultures with $90 \%$ viability and more than $60 \times 10^{6}$ cells were frozen or transferred for further expansion in the rapid expansion protocol (REP). Sterility testing and microbiological control were performed on all TIL cultures before freezing or expansion.

TIL bulk cultures were selected for rapid expansion based on proliferative capacity (the fastest growing cultures) and the highest percentage of CD3+, CD45RO+, CCR7+/- and CD8+ phenotypic markers. TILs were cocultured with allogeneic irradiated peripheral blood monocytes (PBMCs) serving as feeder cells together with culture medium AIM-V, anti-CD3 antibody (OKT-3, Cilag AG, Suisse), and IL-2 in upright T175 flasks. At day 14 the expansion rate had increased by more than 
1000 fold and the cells were harvested and infused in the lymphodepleted patient.

\section{Immunological assays}

Fluorochrome-conjugated antibodies for flow cytometry were the following: CD3, CD4, CD8, CD27, CD45RO, CCR7, IFN- $\gamma$, TNF- $\alpha$, and CD107a (BD, Brøndby, Denmark).

The infusion product and PBMCs obtained before and after treatment from each patient were tested for reactivity against short-term cultured autologous melanoma cell lines (when available), generated from the same specimen used for TIL generation by serial passage of adherent cells [14], or against a panel of 4 to 8 HLA-A matched allogeneic melanoma cell lines. In addition, infusion products were also tested for reactivity against a panel of tumor-derived peptides. The following techniques have been applied.

\section{Intracellular cytokine staining (ICS)}

A flow cytometry-based assay was performed in order to depict the production of cytokines when cells from the infusion product were co-cultured with 1) tumor cell lines, as previously described [14] or with 2) mRNA-transfected autologous DCs: 1) Co-culture with tumor cell lines: TILs were cultured for 5 hours at $37^{\circ} \mathrm{C}$ with $5 \% \mathrm{CO}_{2}$ in air in the presence or absence of melanoma cells at an effector/target ratio of 3:1. 2) Co-culture with mRNA-transfected autologous DCs: One patient (patient 11) had previously been included in a clinical phase I protocol at our center (ClinicalTrials.gov ID: NCT00978913) in which DCs transfected with mRNA encoding p53, survivin or hTERT were evaluated in patients with metastatic breast cancer or malignant melanoma (Additional file 1). TILs from this patient were cultured for 5 hours with i) the DC-vaccine, ii) autologous DCs transfected with p53, survivin and hTERT mRNA, iii) autologous DCs transfected with single mRNA and iv) autologous DCs transfected with mock mRNA (i.e. negative control) at an effector/target ratio of 10:1. Staphylococcal Enterotoxin B (SEB) (Sigma-Aldrich, $5 \mu \mathrm{g} / \mathrm{ml}$ final concentration) was used as positive control. In selected analyses anti-CD107a (BD, $0.03 \mathrm{ug} / \mathrm{ml}$ final concentration) was added at the beginning of the incubation. GolgiPlug (Sigma-Aldrich) was added at a dilution of 1:1000 after the first hour of incubation. After 4 additional hours cells were washed twice with PBS, stained with Fixable Viability Dye (Ebiosciences) and with antibodies directed to surface markers. Cells were washed one additional time, fixed overnight, permeabilized and subsequently stained with antibodies for intracellular cytokines. Cells were analyzed using a BD FACSCanto II flow cytometer. At least $1 \times 10^{5}$ TILs or lymphocytes were acquired. Analysis was performed with BD FacsDiva Software. Responding cells were defined as those who stained double positive for IFN- $\gamma$ and TNF- $\alpha$.

\section{ELIspot assays}

An IFN- $\gamma$ ELIspot assay was performed to quantify the number of TILs responding to 1) tumor-associated peptides, as previously described $[14,15]$ or to 2 ) mRNA transfected autologous DCs.

Briefly, nitrocellulose bottomed 96 well plates (Multiscreen MAIP N45, Millipore, Copenhagen, Denmark) were coated with IFN- $\gamma$ capture antibody (1-DIK, Mabtech, Nacka Strand, Sweden). The wells were washed, blocked with X-VIVO 15 medium and TILs were added in triplicates at different cell concentrations. 1) TILs responding to tumor-associated peptides: TILs were cultured for 4 hours at $37^{\circ} \mathrm{C}$ with $5 \% \mathrm{CO}_{2}$ in air with or without tumor-associated peptides (final concentration $5 \mu \mathrm{M}$ ). 2) TILs responding to mRNA-transfected autologous DCs: TILs were cultured for 4 hours at $37^{\circ} \mathrm{C}$ with $5 \% \mathrm{CO}_{2}$ in air with i) the DC-vaccine, ii) autologous DCs transfected with p53, survivin and hTERT mRNA, iii) autologous DCs transfected with single mRNA and iv) autologous DCs transfected with mock mRNA (i.e. negative control). After addition of secondary biotinylated antibody (7-B6-1-Biotin, Mabtech) and Streptavidin-enzyme conjugates (Streptavidin-ALP, Mabtech), the enzyme substrate nitro blue tetrazolium/5-bromo-4-chloro-3-indolyl phosphate (NBT/ BCIP, Mabtech) was added to each well and the reactions were stopped with tap water. Spots were counted with the ImmunoSpot Series 2.0 Analyzer (CTL Analyzers). A positive response was defined as more than twice the background and at least 50 spots/well.

\section{MHC-multimer staining}

To screen for reactivity against a large panel of melanoma associated peptides we used flow cytometry based detection of MHC multimer binding $\mathrm{T}$ cells by a combinatorial encoding technique [16].

Peptides were purchased from Pepscan (Pepscan Presto BV, Lelystad, Netherlands) and dissolved to $10 \mathrm{mM}$ in DMSO. Recombinant MHC heavy chains and $\beta 2$ microglobulin light chain were produced in Escherichia coli and refolded with conditional ligands, as described by Hadrup et al. [17]. Specific peptide-MHC complexes were produced by UV-mediated peptide exchange of conditional ligands $[17,18]$. The conditional ligands were synthesized as previously described [18-20]. MHC multimers were generated using 8 different streptavidin (SA)-fluorochrome conjugates (SA-PE, SA-APC, SA-PE-Cy7 (BioLegend, San Diego, CA, USA), SA-quantum dot (Qdot)585, SA-Qdot605, SA-Qdot625, SA-Qdot655 and SA-Qdot705 (Invitrogen)). Each peptide-MHC multimer was generated in two different colors, which allows a two-color coding upon staining of specific $\mathrm{T}$ cells, as described [16]. This 
leads to 28 unique two-color codes, of which 27 are functional. These are used for staining of $27 \mathrm{~T}$ cell populations in 1 sample. Eight panels were prepared for analysis of 175 melanoma-associated T cell epitopes (10 HLA-A1, 146 HLA-A2, 11 HLA-A3, 3 HLA-A11 and 5 HLA-B7 epitopes) [21]. Eighteen virus-derived $\mathrm{T}$ cell epitopes were included as positive control of the method.

All $\mathrm{T}$ cell stainings were performed on cryopreserved material. Up to $10^{6}$ cells per sample were stained with 1 MHC multimer panel for $15 \mathrm{~min}$ at $37^{\circ} \mathrm{C}$ and $5 \% \mathrm{CO}_{2}$. Next, cells were stained with anti-CD8-Alexa Fluor 700 (Biolegend), dump channel antibodies (CD4-, CD14-, CD16-, CD19-FITC (BD) and CD40-FITC (AbD SeroTec, Oxford, UK)) and a dead cell marker (LIVE/DEAD Fixable Near-IR, Invitrogen) for $30 \mathrm{~min}$ on ice. Final staining volume was $100 \mu \mathrm{l}$. Subsequently, cells were washed twice with PBS containing $2 \%$ fetal bovine serum (FBS) and resuspended in $50 \mu \mathrm{l}$ PBS containing 2\% FBS. Data acquisition was performed on an LSR-II flow cytometer (BD), and data analysis was carried out using FACSDiva software (BD). Responses were defined as a minimum of 10 spots and a minimum of $0.002 \%$ of $\mathrm{CD}^{+} \mathrm{T}$ cells. All responses were verified in a validation screen, using different color-codes for the given MHC multimer specificity.

\section{Statistical analysis}

Survival was defined as the time from initiation of treatment until death or last date of follow-up (March $1^{\text {st }}$, 2012). Time from treatment initiation until exclusion from the trial due to disease progression was defined as time to progression (TTP).

\section{Results}

\section{Patient characteristics}

Eleven patients with metastatic malignant melanoma were enrolled from June 2009 till June 2011. Six of the 11 included patients were treated according to the protocol. All patients were previously treated with high-dose IL-2 according to an intravenous decrescendo regimen previously described by Keilholz et al. [22]. Demographic data for these 6 patients are depicted in Table 1 .

From 1 of the 11 patients TIL cultures were not established. Two patients developed large symptomatic brain metastases during the time of TIL culturing and 2 patients had rapid disease progression after tumor resection. They were therefore excluded from the trial before treatment initiation. Thus, 5 patients were included in the trial and had tumor resected but were not treated.

\section{Clinical results}

Of the 6 treated patients, 2 patients achieved a complete response (CR), 2 patients had stable disease (SD) and 2 patients progressed rapidly (Table 2).
Patient 1 had a brain metastasis surgically excised prior to inclusion in this trial. At time of inclusion the patient had disseminated disease limited to lymph nodes in the pelvis and 1 of these were removed for the preparation of TILs. Because of post-surgery complications with abscess formation and a peripheral deep venous thrombosis cells were frozen until the patient had recovered. After therapy this patient had slow regression of the metastases leading to a negative PET/CT scan $1 \frac{1}{2}$ years after treatment. This patient is continuously in complete remission 30 months after treatment.

Patient 11 was initially included in a dendritic cell vaccination protocol but because of large metastases on the neck and cheek the patient underwent palliative plastic surgery. Tumor material was sent to the laboratory and TIL cultures were established and frozen for later use. Four months later the patient progressed on the initial treatment and was subsequently included in this protocol. Eight weeks after T-cell infusion there were no sign of disease and previous PET-positive lesions were negative (Figure $1 \mathrm{~b}$ ). This patient is in ongoing complete remission 10 months after therapy.

Patient 3 had SD on the $1^{\text {st }}$ evaluation scan but 4 months after T-cell therapy an increase in tumor burden of $26 \%$ led to exclusion from the protocol. Also patient 7 had SD but developed a new metastasis 5 months after therapy and was therefore excluded due to progressive disease (PD). Patient 2 and 5 had PD at $1^{\text {st }}$ evaluation 8 weeks after therapy.

In total, the 6 patients have a median TTP of 8.2 months (range 2-30 months) and an overall survival (OS) of 12 months (range 5-30 months) with 2 ongoing complete responses (Table 2).

\section{Toxicity}

In general, toxicity grade 3-4 (according to Common Terminology Criteria for Adverse Events (CTCAE) v. 3.0) was related to the lymphodepleting chemotherapy with gastrointestinal symptoms, fatigue and low blood cell counts. All patients had a grade 2 anemia and received blood transfusions, 1 patient had thrombocytopenia and received platelet transfusions and all patients had grade 4 leucopenia, neutropenia and lymphopenia (Table 3).

Notably, very low sodium levels were observed in the first patients during administration of Cyclophosphamide. We found that restriction of oral water intake during infusion of Cyclophosphamide could control the sodium level in the following patients.

The infusion of TILs led to fever and chills for most of the patients. Two patients reacted to the infusion of TILs with high blood pressure and tachycardia. Symptoms were treated with morphine, antihistamines and oxygen and relieved after a few minutes. 
Table 1 Patient demographics

\begin{tabular}{|c|c|c|c|c|c|c|c|c|}
\hline $\begin{array}{l}\text { Patient } \\
\text { number }\end{array}$ & Age(years) & Sex & HLA- type & PS & Previous treatments & Tumor burden $(\mathrm{cm})$ & AJCC stage & Metastatic sites \\
\hline 1 & 60 & $\mathrm{~F}$ & A2 & 0 & IL2/INF, brain surgery & 3.9 & $\mathrm{M} 1 \mathrm{C}$ & $\mathrm{LN}_{\text {, } \text { brain }^{\mathrm{a}}}$ \\
\hline 2 & 47 & M & $\mathrm{A} 2 / \mathrm{A} 3$ & 0 & IL2/IFN, DC-vac, abdominal surgery & 22.8 & M1c & $\mathrm{LN}$, intestines \\
\hline 3 & 62 & M & $\mathrm{A} 3 / \mathrm{A} 11$ & 0 & IL2/IFN, DC-vac & 15.5 & M1c & SC, lung, stomach, gall bladder \\
\hline 6 & 36 & M & $\mathrm{A} 2$ & 0 & IL2/IFN & 8.6 & M1c & LN, liver, bone \\
\hline 7 & 61 & M & A2/A24 & 0 & IL2/INF, CD137, DC-vac, brain surgery & 19.8 & M1c & $\mathrm{LN}$, lung, bone, brain ${ }^{\mathrm{a}}$ \\
\hline 11 & 41 & M & $\mathrm{A} 1 / \mathrm{A} 3$ & 0 & IL2/INF, Ipilimumab, DC-vac & 3.5 & M1a & LN, SC \\
\hline
\end{tabular}

PS: performance status, AJCC: American Joint Committee on Cancer, M:male, F:female, IL2/INF:Interleukin-2/Interferon-a (according to the treatment regimen described by Keilholz et al. ref. 20), DC-vac: dendritic cell vaccine (experimental treatment), CD137:CD137 antibody (experimental treatment), LN: lymphnode metastasis, SC: subcutaneuous metastasis. Tumor burden was defined as the sum of all measurable lesions ( $>1 \mathrm{~cm}$ in longest diameter) up to a maximum of 10

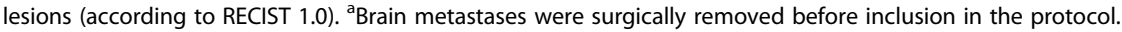

Low-dose IL-2 was well tolerated and all planned injections without dose reductions were given. As expected, patients developed fever during treatment with IL-2 injections and were consequently treated with antibiotics. Other side effects were chills a few hours after injection, nausea and fatigue, although none of these exceeded grade 2 toxicity. Nausea and fatigue were assessed to be related to the previously administered chemotherapy.

\section{TIL characteristics}

Approximately 18 cultures were initiated from each patient and 3-5 of these gave rise to a culture with sufficient growth for further expansion. REP was started at

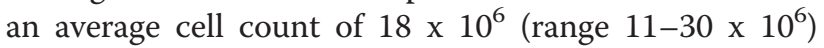
cells after a mean time of 32.5 days (range 24-42 days) in culture. In average $26 \times 10^{9}$ (range $3.4-74.7 \times 10^{9}$ ) TILs were infused in each patient (Table 2).
Phenotype of the infused cells showed that the majority of cells were effector memory $\mathrm{T}$ cells expressing (CD3 (97-100\%) and CD45RO (89-100\%) and low expression of CCR7 (0.6-32\%)). The percentage of CD8 T cells ranged from $47-95 \%$, and between $0.5-8.1 \%$ of the CD8 cells were CD27 positive (Table 2).

Reactivity of the infusion products was tested using several different techniques; including ICS, IFN- $\gamma$ ELIspot assay and MHC multimer staining.

Infused $\mathrm{T}$ cells were tested for production of different cytokines (TNF- $\alpha$ and IFN- $\gamma$ ) when co-cultured with autologous melanoma cell lines ( 2 patients) or a panel of HLA-A matched allogeneic cell lines (4 patients) (Additional file 2). Reactivity of the TILs against autologous tumor from patient 11 is depicted in Figure 1a, upper row. The 2 clinical responding patients (patient 11 tested against an autologous cell line and patient 1 tested against an allogeneic cell line) had higher reactivity than

Table 2 Treatment characteristics and clinical outcome

\begin{tabular}{|c|c|c|c|c|c|c|c|c|c|c|}
\hline \multirow{3}{*}{$\begin{array}{l}\text { Patient } \\
\text { number }\end{array}$} & \multicolumn{7}{|c|}{ Phenotype and functionality of the infusion products } & \multicolumn{3}{|c|}{ Clinical outcome } \\
\hline & $\begin{array}{c}\text { Infused } \\
\text { cells }\end{array}$ & $\mathrm{CD8}^{+}$ & ${\mathrm{CD} 45 \mathrm{RO}^{+}}^{+}$ & $\mathrm{CCR7}^{+}$ & $\mathrm{CD}_{2} 7^{+}$ & Reactivity $^{a}$ & $\begin{array}{l}\text { Total number of } \\
\text { responding CD8 }{ }^{+} \\
T \text { cells infused }\end{array}$ & Response & TTP & OS \\
\hline & $\left(\times 10^{10}\right)$ & (\%) & (\%) & (\%) & (\% of CD8) & (\%) & $\left(x 10^{6}\right)$ & (RECIST) & (mo) & (mo) \\
\hline 1 & 2.9 & 94 & 99.7 & 7.5 & 6.1 & $28.8^{\#}$ & 6460 & CR & $30+$ & $30+$ \\
\hline 2 & 1.8 & 92 & 97.4 & 4.9 & 5.2 & $1.0^{\#}$ & 175 & PD & 2 & 7 \\
\hline 3 & 2.0 & 95 & 99.4 & 6.1 & 0.5 & $0.0^{\#}$ & 7 & SD & 4 & 11.5 \\
\hline 6 & 0.3 & 47 & 98.4 & 3.9 & 1.2 & $0.9^{*}$ & 41 & PD & 2 & 4.6 \\
\hline 7 & 1.3 & 88 & 89 & 31.8 & 3.4 & $0.4^{\#}$ & 44 & SD & 5 & 11 \\
\hline 11 & 7.5 & 95 & 99 & 0.6 & 8.1 & $6.0^{*}$ & 4377 & CR & $10+$ & $10+$ \\
\hline
\end{tabular}

Table showing phenotypic and functional characteristics of the infusion products as well as clinical outcome for the 6 treated patients.

${ }^{a}$ Reactivity meaning tumor-specific CD8+ T cells in \% of infused TILs. Reactivity was calculated by intracellular cytokine staining measuring the percentage of CD8+ T cells expressing TNF- $a$ and IFN- $\gamma$ after co-culture with *autologous tumor cell lines or \#allogeneic melanoma cell lines. For patients tested against several allogeneic melanoma cell lines reactivity against the cell line that resulted in the highest reactivity has been shown (for further details please see Additional file 2). RECIST: Response Evaluation Criteria in Solid Tumors, TTP: time to progression, OS: overall survival, mo: months, CR: complete response, SD: stable disease, PD: progressive disease. 
Table 3 Toxicity

\begin{tabular}{lcccc}
\hline & Grade 1 & Grade 2 & Grade 3 & Grade 4 \\
\hline Performance status & 1 & 4 & 1 & \\
Fatigue & 2 & 3 & 1 & \\
Leucopenia & & & & 6 \\
Neutropenia & & & & 6 \\
Lymphopenia & & & & 6 \\
Thrombopenia & & 6 & 1 & \\
Anemia & & 4 & 1 & \\
Nausea & 2 & 2 & & \\
Diarrhea & 2 & & & \\
Vomiting & 2 & & & \\
Infections & & 6 & & \\
Alopecia & 2 & 1 & & \\
Dermatitis & 3 & & & \\
Allergic reaction & 2 & & & \\
Low sodium levels & & & & \\
\hline
\end{tabular}

No grade 3-4 events were associated with Interleukin-2 treatment. Grade is referring to Common Terminology Criteria for Adverse Events (CTCAE) v. 3.0. Digits in the table are referring to number of patients with the given adverse event.

the non-responding patients (Table 2). Interestingly, a more than 80 fold higher absolute number of tumorspecific $\mathrm{CD}^{+}{ }^{+}$cells in the infusion product was observed among the 2 responding patients compared to the 4 nonresponders $\left(5418 \times 10^{6}\right.$ vs. $67 \times 10^{6} \mathrm{CD}^{+} \mathrm{T}$ cells (mean values)) (Table 2). Reactivity against the tumor cell lines were confirmed for the 2 responding patients by direct IFN- $\gamma$ ELIspot analyses (data not shown).

Reactivity against a selected panel of peptide epitopes from well-characterized melanoma antigens was tested with direct IFN- $\gamma$ ELIspot analyses (Table 4a). In these analyses we found reactivity against $23-60 \%$ of the tested peptides. In addition, we tested for the presence of CD8 $\mathrm{T}$ cells recognizing a large panel of 173 peptides, representing all published epitopes of relevance for melanoma (the full peptide list can be found in Andersen RS et al. [21]). To screen for reactivity against this large panel of melanoma associated peptides a combinatorial encoding technique was applied [16] (Examples of MHC multimer stainings have been presented in Additional file 3). Using this technique, we confirmed only 3 of the responses detected by ELIspot and detected another 8 responses towards a limited set of peptides from this large peptide library (Table 4b). Most of the $\mathrm{T}$ cell responses detected were of low frequency, in concordance with previous published data [21,23], and even this large peptide library is limited in describing the epitope-specificity of the autologous and allogeneic tumor cell recognition observed. There were no correlation between peptide specific reactivity and clinical response.
Immune monitoring

PBMCs from before and after treatment were tested by ICS for reactivity against autologous tumor cell lines when available (patient 11), otherwise the allogeneic melanoma cell lines against which the infusion product had shown highest reactivity were used (patient 1, 2, 3 and 7). No increase in baseline reactivity was seen, except for patient 11 who had no activity when tested at baseline but developed a response 1 week after $\mathrm{T}$ cell infusion which was confirmed after 3 weeks (Figure 1a). This patient had a complete clinical response to the treatment (Figure 1b).

\section{Re-activation of previously activated T cells from a patient treated with a dendritic cell (DC) vaccination}

One patient (patient 11) had previously been included in a clinical phase I trial where DCs transfected with mRNA encoding p53, survivin or hTERT were evaluated in patients with metastatic breast cancer or malignant melanoma (Engell-Noerregaard et al. trial ongoing, see Additional file 1 for further information). Accordingly, we questioned whether the infusion product could elicit immune responses to the mRNA transfected DC-vaccine. For this purpose, TILs from patient 11 were stimulated with either the DC-vaccine or DCs transfected with triple mRNA and vaccine-specific TILs were subsequently analyzed with ELIspot IFN- $\gamma$ release assay and ICS. Using this approach, we were able to detect IFN- $\gamma$ TIL reactivity against the DC-vaccine and transfected DCs in both the ELIspot and ICS assay (Figure 2). Further analysis using single mRNA-transfected DCs as target revealed that the TIL response was predominantly against hTERT-transfected DCs (Figure 2a). This was consistent with the responding TILs detected using the ICS assay (Figure 2b). No response was detected when TILs were stimulated with p53, survivin or mocktransfected DCs (Figure 2).

\section{Discussion}

Herein we report the results from 6 patients treated with lymphodepleting chemotherapy, autologous TILs and very low-doses of IL-2. This trial shows that it is possible to induce complete and long-lasting responses even with the use of low-dose IL-2 that significantly reduced the toxicity of therapy. Today, ACT is only implemented in few clinical centers, but if high-dose IL-2 was not required, it could be possible to offer this therapy more widely and to more patients. With this said, this is a pilot trial including only 6 patients, and whether the doses of IL-2 affects the clinical response rate warrants further study. Thus, larger clinical studies are needed to confirm whether high response rates can be maintained with the use of lower doses of IL-2 in combination with ACT. 


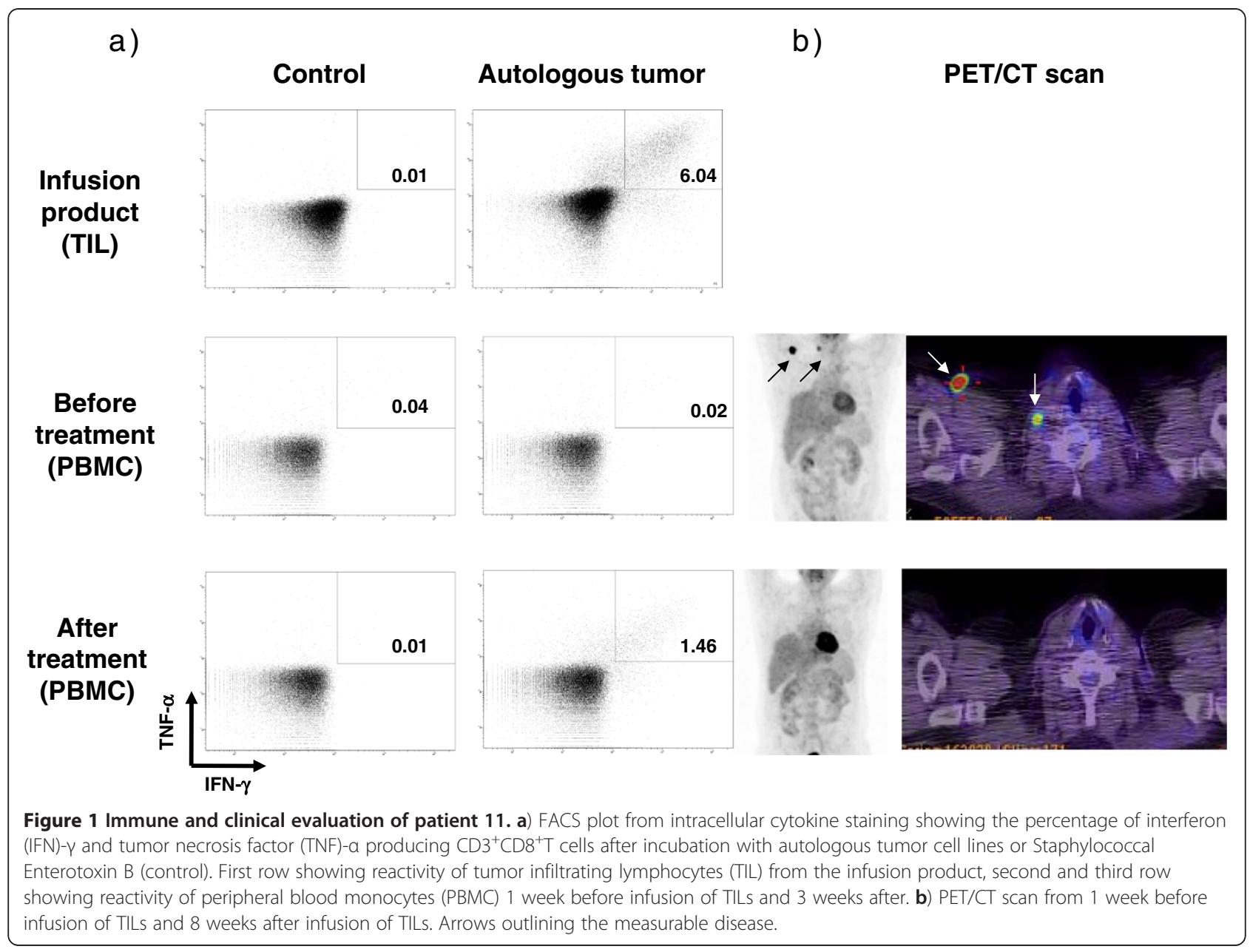

Investigations on the use of low-dose IL-2 in an ACT setting have been performed by others. Yee et al. [24] demonstrated that adoptively transferred $\mathrm{T}$ cell clones targeting melanoma-associated antigens could persist in vivo in response to very low doses of IL-2. Two other groups $[25,26]$ have shown that Melan-A-specific CD8 ${ }^{+}$ $\mathrm{T}$ cells were able to induce long-lasting responses in metastatic melanoma patients and that transferred cells persisted and even expanded in vivo. In these studies the infusion of $\mathrm{T}$ cells was followed by subcutaneous injections of low-dose IL-2 and/or IFN- $\alpha$ suggesting that low-doses of cytokines might well be sufficient to prolong survival of the transferred cells and induce objective clinical responses. This is further underlined by the results from Verdegaal et al. [27] who reported on a clinical study transferring blood derived tumor-specific T- cells into metastatic melanoma patients in combination with low-dose IFN- $\alpha$ still observing long lasting clinical responses. A recently published retrospective report from Ullenhag and colleagues [28] described a cohort of patients treated with ACT and a low dose IL-2 regimen with $2.4 \mathrm{MIU} / \mathrm{m}^{2}$ once a day continuing until progression. Long lasting response in 1 of the patients was reported; however, continuous treatment with IL-2, even in low-doses, might significantly interfere with quality of life for those patients achieving durable responses. Besides, it is questionable whether long-term IL-2 treatment is necessary for continuous tumor control $[8,9]$.

Only 6 of 11 included patients who underwent tumor resection with the intent to treat actually received treatment. In this study, patients were treated with TILs from selected individual cultures resulting in a culturing time (including REP) of about 7-8 weeks. Treating patients with unselected young TILs can decrease the production time to $4-5$ weeks $[8,29]$. Also, the use of engineered cells for costimulatory enhancement during TIL expansion has been described to accelerate TIL growth [30] and hereby decrease the time from surgery to treatment. Accelerated preparation time might reduce the drop-out rate, as 4 out of 5 patients who were not treated in this trial were excluded due to deterioration of performance and/or the appearance of brain metastases awaiting the treatment. Furthermore, methods to improve the reliability of TIL 
Table 4 T-cell responses detected in TIL infusion products

\begin{tabular}{|c|c|c|c|c|c|c|c|}
\hline \multicolumn{8}{|c|}{ a) IFN- $\gamma$ ELlspot analyses } \\
\hline \multicolumn{2}{|c|}{ Patient ID } & 1 & 2 & 3 & 6 & 7 & 11 \\
\hline \multicolumn{2}{|c|}{ HLA-type } & $\mathrm{A} 2$ & $\mathrm{~A} 2 / \mathrm{A} 3$ & $\mathrm{~A} 3, \mathrm{~A} 11$ & $A 2$ & $\mathrm{~A} 2$ & $\mathrm{~A} 1, \mathrm{~A} 3$ \\
\hline \multirow[t]{12}{*}{ A2 } & $B C l-2 W L D$ & NR & 43 & - & NR & 301 & - \\
\hline & $\mathrm{BCl}-\mathrm{X}_{\mathrm{RIA}}$ & NR & 165 & - & NR & 197 & - \\
\hline & hTERTIILA & 180 & 456 & - & 363 & 462 & - \\
\hline & CB9L $2_{A L Y}$ & 232 & 135 & - & 293 & 441 & - \\
\hline & CB9 204|LI & 488 & 502 & - & 325 & 408 & - \\
\hline & NY-ESO $1_{S L L}$ & 180 & 564 & - & 158 & 279 & - \\
\hline & MAGE A1 KVL & NR & 57 & - & NR & 190 & - \\
\hline & MAGE A3 $3_{F L W}$ & 91 & 67 & - & 118 & 250 & - \\
\hline & SUR1M2LML & ND & 96 & - & ND & 349 & - \\
\hline & SUR9 ${ }_{E L T}$ & ND & 62 & - & ND & 274 & - \\
\hline & MART-1 $1_{\text {ELA }}$ & ND & $324^{*}$ & - & $193^{*}$ & NR & - \\
\hline & gp100 & ND & 106 & - & ND & ND & - \\
\hline \multirow[t]{6}{*}{ A3 } & $B C l-x_{R I A}$ & - & 284 & 111 & - & - & 59 \\
\hline & SUR18K10 RIS & - & ND & 112 & - & - & NR \\
\hline & SUR53DLA & - & 96 & ND & - & - & 82 \\
\hline & Rho C (nat) $)_{\text {RAG }}$ & - & ND & 114 & - & - & NR \\
\hline & Rho $C(\bmod )_{R L G}$ & - & ND & 103 & - & - & NR \\
\hline & TAGRLS & - & ND & ND & - & - & $42^{*}$ \\
\hline \multicolumn{2}{|c|}{ Number of responses/total screened } & $5 / 15$ & $14 / 24$ & $4 / 9$ & $6 / 15$ & $9 / 15$ & $3 / 13$ \\
\hline \multicolumn{2}{|c|}{ Background } & 99 & 46 & 86 & $130^{a} / 92^{b}$ & 131 & 29 \\
\hline \multicolumn{8}{|c|}{ b) MHC multimer staining } \\
\hline \multicolumn{2}{|c|}{ Patient ID } & 1 & $2^{c}$ & 3 & 6 & 7 & $11^{d}$ \\
\hline \multicolumn{2}{|c|}{ HLA-type } & A2 & $A 2, A 3, B 7$ & $\mathrm{~A} 3, \mathrm{~A} 11$ & A2 & A2 & $\mathrm{A} 1, \mathrm{~A} 3$ \\
\hline \multirow[t]{5}{*}{ A2 } & MART-1 $1_{\text {ELA }}$ & 0.013 & $0.07^{*}$ & - & $1.10^{*}$ & 0.008 & - \\
\hline & gp100YLE & 0.010 & NR & - & 10.0 & NR & - \\
\hline & gp100kTw & 0.010 & NR & - & & NR & - \\
\hline & gp100/TD & 0.002 & NR & - & 0.018 & NR & - \\
\hline & GnT-V VLP-9 & 0.015 & NR & - & NR & NR & - \\
\hline A3 & $T_{A A G}$ & - & NR & NR & - & - & $0.60^{*}$ \\
\hline \multicolumn{2}{|c|}{ Number of responses/total screened } & $5 / 146$ & $1 / 162$ & $0 / 14$ & $3 / 146$ & $1 / 146$ & $1 / 21$ \\
\hline
\end{tabular}

a) IFN- $\gamma$ ELIspot analyses; Responses are defined as number of spots per $1 \times 10^{5}$ T cells, except for patient $7\left(2.5 \times 10^{4}\right.$ cells) and patient 11 ( $1.25 \times 10^{4}$ cells). Background level shown at the bottom of the table has been subtracted in the shown responses. ${ }^{\mathrm{a} / \mathrm{b}}$ : two different assays have been performed wherefore two background values are present.

b) MHC multimer staining; Antigen-specific T cells are given in percentage of CD8 ${ }^{+} \mathrm{T}$ cells. Examples of MHC multimer stainings can be seen in Additional file 3. ${ }^{\mathrm{c}}$ The TILs analyzed were frozen two days after infusion. ${ }^{\mathrm{d}}$ The TILs analyzed were frozen one day after infusion.

Last row indicates the number of detected responses out of the total number of peptides screened. NR: no reactivity, ND: reactivity testing not done, -: not tested due to HLA-discrepancy.

*Indicating responses found in both methods. nat: natural, mod: modified.

production have been examined in order to diminish the number of patients not treated due to insufficient TIL growth [30,31]. Validation and implementation of these processes will reveal if this can further increase the fraction of treated patients.

The infusion product for each patient was tested for reactivity against a large panel of melanoma antigens. Screening for reactivity against different peptides showed some responses but these were unable to fully explain the anti-tumor reactivity observed. The limited peptide reactivity is in line with recent data, showing recognition of only a small fraction of the described melanomaassociated peptides and predominantly very low frequency of antigen specific $\mathrm{T}$ cell populations [23,32]. Furthermore, only few of the responses detected by IFN- $\gamma$ ELIspot could be confirmed in the assessment by 


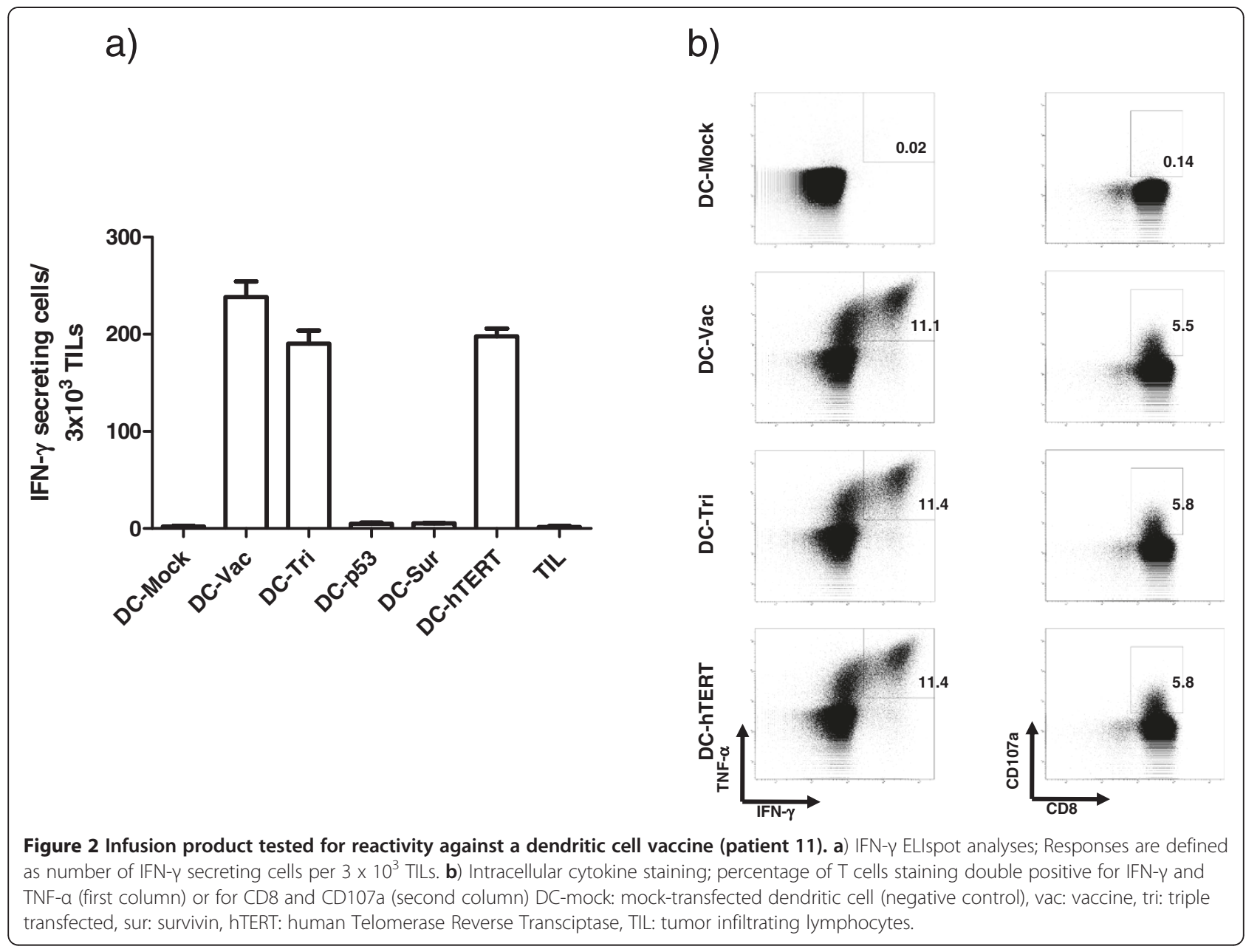

MHC multimers. However, it may be speculated that part of this discrepancy relies to the fact that the majority of the "self-reactive" $\mathrm{T}$ cells posses a very low affinity to the MHC possibly insufficient for MHC-multimer binding, but sufficient for stimulation of IFN- $\gamma$ secretion upon addition of excess amounts of peptide. In addition, a number of reports have shown that IFN- $\gamma$ secretion after stimulation with short peptides may result from CD4 T cells (Eckhart Kämpgen, Erlangen, Germany, personal communication), and the performed IFN- $\gamma$ ELIspot analyses did not discriminate between CD4 and CD8. Nevertheless, the TIL infusion product consisted of mostly CD8 T cells (Table 2) wherefore this would be able to explain only a limited part of the differences in reactivity.

Conclusions on correlation between clinical response and patient demographics or treatment characteristics are not possible with 6 treated patients. However, the 2 responding patients' characteristics differ from the nonresponding patients. Both responding patients had gone through extensive surgery and had, at the time of treatment initiation, only limited disease burden, suggesting that debulking of tumor-mass may play a role for the outcome of TIL therapy using low-dose IL-2. Also, a high percentage of CD8 $\mathrm{T}$ cells and a high number of infused TILs were characteristic for the responding patients (Table 2). Even though several patients, including non-responding patients had a high percentage of CD8 T cells in the infusion product this might, together with other factors such as high reactivity against melanoma cell lines, increase the possibility of obtaining a clinical response. Interestingly, we found that a high absolute number of tumor-reactive $\mathrm{T}$ cells in the infusion product were more than 80 times higher for patients with a clinical response than for non-responders.

Correlations between clinical response and patient demographics or treatment characteristics have been intensively investigated by others. In ACT trials using high dose IL-2 no correlation between tumor burden and clinical response has been observed previously [9] and whether our findings are due to the lower amount of IL-2 given or whether it might just be a coincidence considering the low number of patients treated can not be concluded in this pilot study. Besser et al. [8] also found 
a correlation between the percentage of $\mathrm{CD}^{+} \mathrm{T}$ cells in the infusion product and clinical response as well as between the number of infused cells and clinical response. Longer telomer length, a high percentage of $\mathrm{CD} 8^{+} \mathrm{CD} 27^{+}$ TILs and persistency of the infused cells in the circulation have also been shown to correlate with clinical response [33] wherefore new methods resulting in shorter culturing time (young TILs) has emerged [8].

Future initiatives on how to increase the tumorreactivity of infused TILs should be considered. We have recently shown that IFN- $\gamma$ is able to increase the immunogenicity of melanoma cells thereby restoring the responsiveness in otherwise unresponsive $\mathrm{T}$ cells in clinical TIL products (Donia $\mathrm{M}$ et al. accepted for publication, J Invest Dermatol, 2012) and IFN- $\alpha$ has in a previous study been shown to be able to induce clinical responses in combination with ACT [27]. Also, other agents, such as BRAF inhibitors have been shown to have immune modulating potential [34-36]. Thus, the use of these agents in combination with ACT could have the potential to enhance immunogenicity of tumor cells and thereby increase the fraction of tumor-specific $\mathrm{T}$ cells in the TIL product capable of killing tumor cells.

A high percentage of vaccine-specific $T$ cells were found in the infusion product from a patient previously treated with an mRNA transfected DC vaccine. We hypothesize that vaccine-specific $\mathrm{T}$ cells were induced during the $\mathrm{DC}$ vaccination but were not able to overcome immunosuppressive mechanisms and therefore did not give rise to a clinical significant anti-tumor response. When $\mathrm{T}$ cells were activated and expanded ex-vivo and re-infused into the lymphodepleted patient a clinical response could be established. Further analyses will be performed to clarify whether the vaccine-specific cells are indeed induced during vaccination and whether these cells equal the tumor reacting cells.

\section{Conclusions}

In conclusion, we demonstrate that durable complete responses can be achieved using ACT and short duration of low-dose IL-2. The much less toxic regimen simplifies the clinical setting of this therapy making it more attractive for other centers to establish. Also, the possibility of an association between the absolute number of tumor-reactive $\mathrm{T}$ cells infused and clinical response is shown. This knowledge could be used in the future search for optimizing ACT, with new trials focusing on increasing the tumor-sensitivity to $\mathrm{T}$ cell mediated killing as well as the number of potent tumor-reactive T cells.

Our findings of cancer vaccine-specific $\mathrm{T}$ cells in the infusion product from a patient who subsequently achieved complete response support the idea of inducing anti-tumor $\mathrm{T}$ cells by a cancer vaccine. The technique for subsequent expansion in vitro have been established in a preclinical setting [37] and will be incorporated in a clinical trial initiated in the near future. Also, we have initiated a new trial for metastatic melanoma patients using young-TIL ACT in combination with intermediate doses of IL-2 (ClinicalTrials.gov ID: NCT00937625) with the purpose of defining the most optimal dose of IL-2 for the use in a larger randomized clinical trial.

\section{Additional files}

Additional file 1: Materials and methods on "Transfected dendritic cell based therapy for patients with breast cancer or malignant melanoma" (Engell-Noerregaard et al. trial ongoing, ClinicalTrials. gov ID: NCT00978913).

Additional file 2: Table S1. Showing reactivity of the TIL infusion products. Additional file 3: Figure S1. Example of MHC multimer stainings.

\section{Abbreviations}

ACT: Adoptive cell transfer; TIL: Tumor infiltrating lymphocytes; IL2: Interleukin-2; IFN: Interferon; TNF: Tumor necrosis factor; RECIST: Response evaluation criteria in solid tumors; CTCAE: Common terminology criteria for adverse events; CT: Computed tomography; PET: Positron emission tomography; REP: Rapid expansion protocol; PBMC: Peripheral blood monocytes; HLA: Human leucocyte antigen; DC: Dendritic cell;

SEB: Staphylococcal enterotoxin B; ELIspot: Enzyme-linked immunosorbent spot; CR: Complete response; PR: Partial response; SD: Stable disease; PD: Progressive disease; TTP: Time to progression; OS: Overall survival.

\section{Competing interests}

The authors declare that they have no competing interests.

\section{Authors' contributions}

EE participated in conception and design, acquisition of data, and analysis and interpretation of data as well as drafting the manuscript. TZI, LEN and LRH participated in acquisition of clinical data and the evaluation of these. $\mathrm{NJ}$ participated in the conception and design, preparation of clinical grade TILs and carried out the ELIspot analyses. MD carried out some of the ELIspot analyses and all intracellular staining analyses and participated in analysis and interpretation of data. ÖM carried out the ELIspot analysis regarding $\mathrm{mRNA}$ transfected DCs and participated in analysis and interpretation of these data. RSA and SRH did the MHC multimer staining and participated in analysis and interpretation of these data. MHA and PtS participated in conception and design and interpretation of data. IMS participated in conception and design, analysis and interpretation of data and helped to draft the manuscript. All authors revised, read and approved the final manuscript.

\section{Acknowledgements}

The authors thank the technicians at the laboratorium of Hematology and the staff at the department of Oncology. For review of the CT scans we thank radiologist Helle Hjort Johannesen. Furthermore, the Surgical branch, National Cancer Institute, Bethesda, Maryland is thanked for sharing protocols and knowledge.

The study was supported by grants from Aase and Ejner Danielsens Foundation, the Danish Cancer Society, the Lundbeck Foundation, and the Capital Region of Denmark Research Foundation. The funding body had no role in design, in the collection, analysis, and interpretation of data, or in the writing of the manuscript.

\section{Author details}

${ }^{1}$ CCIT, Center for Cancer Immune Therapy, Department of Hematology, Copenhagen University Hospital, Herlev, Denmark. Department of Oncology, Copenhagen University Hospital, Herlev, Denmark. ${ }^{3}$ Department of Biomedical Sciences, University of Catania, Catania, Italy. ${ }^{4}$ Department of Plastic Surgery, Copenhagen University Hospital, Herlev, Denmark. 
Received: 2 May 2012 Accepted: 14 August 2012

Published: 21 August 2012

\section{References}

1. American Cancer Society: Cancer facts and figures. 2010. www.cancer.org

2. Hodi FS, O'Day SJ, McDermott DF, Weber RW, Sosman JA, Haanen JB, Gonzalez R, Robert C, Schadendorf D, Hassel JC, Akerley W, van den Eertwegh AJ, Lutzky J, Lorigan P, Vaubel JM, Linette GP, Hogg D, Ottensmeier CH, Lebbe C, Peschel C, Quirt I, Clark JI, Wolchok JD, Weber JS, Tian J, Yellin MJ, Nichol GM, Hoos A, Urba WJ: Improved survival with ipilimumab in patients with metastatic melanoma. N Engl J Med 2010, 363:711-723.

3. Robert C, Thomas L, Bondarenko I, O'Day S, JW MD, Garbe C, Lebbe C, Baurain JF, Testori A, Grob JJ, Davidson N, Richards J, Maio M, Hauschild A, Miller WH Jr, Gascon P, Lotem M, Harmankaya K, Ibrahim R, Francis S, Chen TT, Humphrey R, Hoos A, Wolchok JD: Ipilimumab plus dacarbazine for previously untreated metastatic melanoma. N Engl J Med 2011, 364:2517-2526.

4. Chapman PB, Hauschild A, Robert C, Haanen JB, Ascierto P, Larkin J, Dummer R, Garbe C, Testori A, Maio M, Hogg D, Lorigan P, Lebbe C, Jouary T, Schadendorf D, Ribas A, O'Day SJ, Sosman JA, Kirkwood JM, Eggermont AM, Dreno B, Nolop K, Li J, Nelson B, Hou J, Lee RJ, Flaherty KT, McArthur GA: Improved survival with vemurafenib in melanoma with BRAF V600E mutation. N Engl J Med 2011, 364:2507-2516.

5. Topalian Suzanne L, Drake Charles G, Pardoll Drew M: Targeting the PD-1/ B7-H1(PD-L1) pathway to activate anti-tumor immunity. Curr Opin Immunol 2012, 24:207-212.

6. Topalian SL, Hodi FS, Brahmer JR, Gettinger SN, Smith DC, McDermott DF, Powderly JD, Carvajal RD, Sosman JA, Atkins MB, Leming PD, Spigel DR, Antonia SJ, Horn L, Drake CG, Pardoll DM, Chen L, Sharfman WH, Anders RA, Taube JM, McMiller TL, Xu H, Korman AJ, Jure-Kunkel M, Agrawal S, McDonald D, Kollia GD, Gupta A, Wigginton JM, Sznol M: Safety, Activity, and Immune Correlates of Anti-PD-1 Antibody in Cancer. N Engl J Med 2012, 366(26):2443-2453.

7. Flaherty KT, Robert C, Hersey P, Nathan P, Garbe C, Milhem M, Demidov LV, Hassel JC, Rutkowski P, Mohr P, Dummer R, Trefzer U, Larkin JM, Utikal J, Dreno B, Nyakas M, Middleton MR, Becker JC, Casey M, Sherman LJ, Wu FS, Ouellet D, Martin AM, Patel K, Schadendorf D: Improved Survival with MEK Inhibition in BRAF-Mutated Melanoma. N Engl J Med 2012, 367(2):107-114.

8. Besser MJ, Shapira-Frommer R, Treves AJ, Zippel D, Itzhaki O, Hershkovitz L, Levy D, Kubi A, Hovav E, Chermoshniuk N, Shalmon B, Hardan I, Catane R, Markel G, Apter S, Ben-Nun A, Kuchuk I, Shimoni A, Nagler A, Schachter J: Clinical responses in a phase II study using adoptive transfer of shortterm cultured tumor infiltration lymphocytes in metastatic melanoma patients. Clin Cancer Res 2010, 16:2646-2655.

9. Rosenberg SA, Yang JC, Sherry RM, Kammula US, Hughes MS, Phan GQ, Citrin DE, Restifo NP, Robbins PF, Wunderlich JR, Morton KE, Laurencot CM, Steinberg SM, White DE, Dudley ME: Durable complete responses in heavily pretreated patients with metastatic melanoma using T-cell transfer immunotherapy. Clin Cancer Res 2011, 17:4550-4557.

10. Dudley ME, Wunderlich JR, Yang JC, Sherry RM, Topalian SL, Restifo NP Royal RE, Kammula U, White DE, Mavroukakis SA, Rogers L, Gracia GJ, Jones SA, Mangiameli DP, Pelletier MM, Gea-Banacloche J, Robinson MR, Berman DM, Filie AC, Abati A, Rosenberg SA: Adoptive cell transfer therapy following non-myeloablative but lymphodepleting chemotherapy for the treatment of patients with refractory metastatic melanoma. J Clin Oncol 2005, 23:2346-2357.

11. Dudley ME, Wunderlich JR, Yang JC, Hwu P, Schwartzentruber DJ, Topalian SL, Sherry RM, Marincola FM, Leitman SF, Seipp CA, Rogers-Freezer L, Morton KE, Nahvi A, Mavroukakis SA, White DE, Rosenberg SA: A phase I study of nonmyeloablative chemotherapy and adoptive transfer of autologous tumor antigen-specific T lymphocytes in patients with metastatic melanoma. J Immunother 2002, 25:243-251.

12. Dudley ME, Wunderlich JR, Shelton TE, Even J, Rosenberg SA: Generation of tumor-infiltrating lymphocyte cultures for use in adoptive transfer therapy for melanoma patients. J Immunother 2003, 26:332-342.

13. Junker N, Straten PT, Andersen MH, Svane IM: Characterization of ex vivo expanded tumor infiltrating lymphocytes from patients with malignant melanoma for clinical application. J Skin Cancer 2011, 2011:574695.
14. Donia M, Junker N, Ellebaek E, Andersen MH, Straten PT, Svane IM: Characterization and Comparison of Standard and Young TumourInfiltrating Lymphocytes for Adoptive Cell Therapy at a Danish Translational Research Institution. Scand I Immunol 2012, 75:157-167.

15. Junker $\mathrm{N}$, Kvistborg $\mathrm{P}$, Kollgaard T, Straten $\mathrm{P}$, Andersen MH, Svane IM: Tumor associated antigen specific T-cell populations identified in ex vivo expanded TIL cultures. Cell Immunol 2012, 273:1-9.

16. Hadrup SR, Bakker AH, Shu CJ, Andersen RS, Van Veluw J, Hombrink P, Castermans E, Thor Straten P, Blank C, Haanen JB, Heemskerk MH, Schumacher TN: Parallel detection of antigen-specific T-cell responses by multidimensional encoding of MHC multimers. Nat Methods 2009, 6:520-526.

17. Hadrup SR, Toebes M, Rodenko B, Bakker AH, Egan DA, Ovaa H, Schumacher TN: High-throughput T-cell epitope discovery through MHC peptide exchange. Methods Mol Biol 2009, 524:383-405.

18. Rodenko B, Toebes M, Hadrup SR, van Esch WJ, Molenaar AM, Schumacher TN, Ovaa H: Generation of peptide-MHC class I complexes through UVmediated ligand exchange. Nat Protoc 2006, 1:1120-1132.

19. Bakker AH, Hoppes R, Linnemann C, Toebes M, Rodenko B, Berkers CR, Hadrup SR, van Esch WJ, Heemskerk MH, Ovaa H, Schumacher TN: Conditional MHC class I ligands and peptide exchange technology for the human MHC gene products HLA-A1, -A3, -A11, and -B7. Proc Natl Acad Sci USA 2008, 105:3825-3830.

20. Toebes M, Coccoris M, Bins A, Rodenko B, Gomez R, Nieuwkoop NJ, van de Kasteele W, Rimmelzwaan GF, Haanen JB, Ovaa H, Schumacher TN: Design and use of conditional MHC class I ligands. Nat Med 2006, 12:246-251.

21. Andersen Rikke S, Thrue Charlotte A, Junker N, Lyngaa R, Donia M, Ellebaek E, Svane Inge M, Schumacher Ton N, Thor Straten P, Hadrup Sine R: Dissection of T-cell Antigen Specificity in Human Melanoma. Cancer Res 2012, 72:1642-1650.

22. Keilholz U, Goey SH, Punt CJ, Proebstle TM, Salzmann R, Scheibenbogen C, Schadendorf D, Lienard D, Enk A, Dummer R, Hantich B, Geueke AM, Eggermont AM: Interferon alfa-2a and interleukin-2 with or without cisplatin in metastatic melanoma: a randomized trial of the European Organization for Research and Treatment of Cancer Melanoma Cooperative Group. J Clin Oncol 1997, 15:2579-2588.

23. Kvistborg P, Shu Chengyi J, Heemskerk B, Fankhauser M, Thrue Charlotte A, Toebes M, Van Rooij N, Linnemann C, Van Buuren M, Urbanus Jos HM, Beltman J, Thor Straten P, Li Y, Robbins P, Besser M, Schachter J, Kenter G, Dudley Mark E, Rosenberg Steven A, Haanen John BAG, Hadrup Sine R, Schumacher Ton NM: TIL therapy broadens the tumor-reactive CD8+ T cell compartment in melanoma patients. Oncolmmunology 2012, 1:0-9.

24. Yee C, Thompson JA, Byrd D, Riddell SR, Roche P, Celis E, Greenberg PD: Adoptive T cell therapy using antigen-specific CD8+ T cell clones for the treatment of patients with metastatic melanoma: in vivo persistence, migration, and antitumor effect of transferred T cells. Proc Natl Acad Sci USA 2002, 99:16168-16173.

25. Khammari A, Labarriere $N$, Vignard V, Nguyen JM, Pandolfino MC, Knol AC, Quereux G, Saiagh S, Brocard A, Jotereau F, Dreno B: Treatment of metastatic melanoma with autologous Melan-A/MART-1-specific cytotoxic T lymphocyte clones. J Invest Dermatol 2009, 129:2835-2842.

26. Mackensen A, Meidenbauer N, Vogl S, Laumer M, Berger J, Andreesen R: Phase I study of adoptive T-cell therapy using antigen-specific CD8+ T cells for the treatment of patients with metastatic melanoma. J Clin Oncol 2006, 24:5060-5069.

27. Verdegaal EM, Visser M, Ramwadhdoebe $T H$, van der Minne CE, van Steijn JA, Kapiteijn E, Haanen JB, van der Burg SH, Nortier JW, Osanto S: Successful treatment of metastatic melanoma by adoptive transfer of blood-derived polyclonal tumor-specific CD4+ and CD8+ T cells in combination with low-dose interferon-alpha. Cancer Immunol Immunother 2011, 60:953-963.

28. Ullenhag G, Sadeghi A, Carlsson B, Ahlstrom H, Mosavi F, Wagenius G, Totterman TH: Adoptive T-cell therapy for malignant melanoma patients with TILs obtained by ultrasound-guided needle biopsy. Cancer Immunology, Immunotherapy 2012, 61(5):725-732.

29. Besser MJ, Shapira-Frommer R, Treves AJ, Zippel D, Itzhaki O, Schallmach E, Kubi A, Shalmon B, Hardan I, Catane R, Segal E, Markel G, Apter S, Nun AB, Kuchuk I, Shimoni A, Nagler A, Schachter J: Minimally cultured or selected autologous tumor-infiltrating lymphocytes after a lympho-depleting chemotherapy regimen in metastatic melanoma patients. J Immunother 2009, 32:415-423. 
30. Friedman KM, Devillier LE, Feldman SA, Rosenberg SA, Dudley ME: Augmented lymphocyte expansion from solid tumors with engineered cells for costimulatory enhancement. J Immunother 2011, 34:651-661.

31. Joseph RW, Peddareddigari VR, Liu P, Miller PW, Overwijk WW, Bekele NB, Ross MI, Lee JE, Gershenwald JE, Lucci A, Prieto VG, McMannis JD, Papadopoulos N, Kim K, Homsi J, Bedikian A, Hwu WJ, Hwu P, Radvanyi LG: Impact of clinical and pathologic features on tumor-infiltrating lymphocyte expansion from surgically excised melanoma metastases for adoptive T-cell therapy. Clin Cancer Res 2011, 17:4882-4891.

32. Andersen RS, Thrue CA, Junker N, Lyngaa R, Donia M, Ellebaek E, Svane IM, Schumacher TN, Straten PT, Hadrup SR: Dissection of T cell antigen specificity in human melanoma. Cancer Res 2012, 72(7):1642-1650.

33. Dudley ME, Yang JC, Sherry R, Hughes MS, Royal R, Kammula U, Robbins PF, Huang J, Citrin DE, Leitman SF, Wunderlich J, Restifo NP, Thomasian A, Downey SG, Smith FO, Klapper J, Morton K, Laurencot C, White DE, Rosenberg SA: Adoptive cell therapy for patients with metastatic melanoma: evaluation of intensive myeloablative chemoradiation preparative regimens. J Clin Oncol 2008, 26:5233-5239.

34. Boni A, Cogdill AP, Dang P, Udayakumar D, Njauw CN, Sloss CM, Ferrone CR, Flaherty KT, Lawrence DP, Fisher DE, Tsao H, Wargo JA: Selective BRAFV600E inhibition enhances T-cell recognition of melanoma without affecting lymphocyte function. Cancer Res 2010, 70:5213-5219.

35. Comin-Anduix B, Chodon T, Sazegar H, Matsunaga D, Mock S, Jalil J, EscuinOrdinas H, Chmielowski B, Koya RC, Ribas A: The oncogenic BRAF kinase inhibitor PLX4032/RG7204 does not affect the viability or function of human lymphocytes across a wide range of concentrations. Clin Cancer Res 2010, 16:6040-6048.

36. Hong DS, Vence LM, Falchook GS, Radvanyi LG, Liu C, Goodman VL, Legos JJ, Blackman SC, Scamardo AT, Kurzrock R, Lizee G, Hwu P: BRAF(V600) inhibitor GSK2118436 targeted inhibition of mutant BRAF in cancer patients does not impair overall immune competency. Clin Cancer Res 2012, 18(8):2326-2335.

37. Brimnes M, Gang A, Donia M, Thor Straten P, Svane I, Hadrup S: Generation of autologous tumor-specific T cells for adoptive transfer based on vaccination, in vitro restimulation and CD3/CD28 dynabead-induced $T$ cell expansion. Cancer Immunology, Immunotherapy, 61(8):1221-1231.

doi:10.1186/1479-5876-10-169

Cite this article as: Ellebaek et al:: Adoptive cell therapy with autologous tumor infiltrating lymphocytes and low-dose Interleukin-2 in metastatic melanoma patients. Journal of Translational Medicine 2012 10:169.

\section{Submit your next manuscript to BioMed Central and take full advantage of:}

- Convenient online submission

- Thorough peer review

- No space constraints or color figure charges

- Immediate publication on acceptance

- Inclusion in PubMed, CAS, Scopus and Google Scholar

- Research which is freely available for redistribution 